\title{
Does C-reactive protein predict saphenous vein graft patency?
}

Hwee Teoh, PhD, Adrian Quan, MPhil, and Subodh Verma, MD, PhD

See related article on page 335 .

From the Division of Cardiac Surgery and Keenan Research Centre, Li Ka Shing Knowledge Institute, St Michael's Hospital, University of Toronto, Toronto, Ontario, Canada.

Received for publication March 10, 2007; accepted for publication March 15, 2007.

Address for reprints: Subodh Verma, MD, PhD, Division of Cardiac Surgery, Suite 8-003F, Bond Wing, St Michael's Hospital, 30 Bond St, Toronto, Ontario, Canada M5B 1W8 (E-mail: subodh.verma@ sympatico.ca).

J Thorac Cardiovasc Surg 2007;134:277-9

$0022-5223 / \$ 32.00$

Copyright $\odot 2007$ by The American Association for Thoracic Surgery

doi:10.1016/j.jtcvs.2007.03.025
I $\mathrm{n}$ this issue, Momin and colleagues ${ }^{1}$ present timely translational evidence that preoperative $\mathrm{C}$-reactive protein (CRP) levels may predict the functionality and patency of saphenous vein grafts (SVGs) after coronary artery bypass graft $(\mathrm{CABG})$ procedures. Endothelial function was examined in saphenous vein segments from patients undergoing CABG who had been treated with simvastatin preoperatively. CRP levels emerged as the only independent (negative) correlate of endothelial function, and they consequently open the window to the possibility that patients with elevated CRP may be predisposed to postoperative SVG occlusions among other de novo atherosclerosis-related complications.

Although the immediate procedural success with SVGs is comparable with that of arterial grafts, the greater susceptibility of SVGs to accelerated intimal hyperplasia and atherosclerosis remains a limiting factor. Improving endothelial function is an important therapeutic approach in limiting aberrant saphenous vein remodeling.

Notwithstanding the small cohort size of 76 subjects and some interpretational limitations, Momin and colleagues ${ }^{1}$ are to be congratulated for evaluating how CRP (a critical player in inflammatory processes and a biomarker of atherosclerosis) alters SVG vasoresponsiveness and how this, in turn, may influence the efficacy of SVGs. Insight on the interplay between serum CRP concentrations and SVG longevity are unfortunately lacking and would have greatly strengthened this work. Inasmuch as inflammation is increasingly recognized as the crux of atherosclerosis, it would have been prudent for the authors to also monitor CRP values perioperatively and postoperatively. Concurrent expansion of the inflammatory marker panel studied to include serum amyloid A and fibrinogen (among others) that are closely associated with the pathogenesis of atherosclerosis would also have been of great interest. Accordingly, a prospective study encompassing angiographic follow-ups coupled with measurements of serum CRP and other endogenous inflammatory agents in this and other similar cohorts may be warranted.

Prior CABG trials provide compelling evidence that graft patency is superior if statin regimens are initiated preoperatively. Fewer repeat revascularization procedures were performed in these patients and occurrences of ischemic cardiovascular events were decreased. Currently, the ultimate target of statin treatments is to attain low-density lipoprotein (LDL) levels of less than $100 \mathrm{mg} / \mathrm{dL}$. The study by Momin and coworkers ${ }^{1}$ refocuses this school of thought and reminds us that the benefits of statins are also deeply rooted in improved endothelial function, dampened inflammation, and reduced thrombosis. ${ }^{2}$

Prospective epidemiologic studies have repeatedly proven that circulating highsensitivity CRP is an independent predictor of cardiovascular disease risk and mortality. More interestingly, high-sensitivity CRP levels have been demonstrated to have greater prognostic value than that of LDL in predicting future cardiovascular 
events. ${ }^{3}$ As such, the Centers for Disease Control and Prevention and the American Heart Association have now made recommendations on the application of high-sensitivity CRP for the assessment of cardiovascular risk. The results reported by Momin and coworkers ${ }^{1}$ support this line of thought and emphasize that perhaps aggressive management of preoperative CRP levels may be one factor in limiting SVG failure.

The endothelium acts as an interface for the blood and the underlying vascular smooth vessel layer. Under normal conditions, this dynamic organ releases a variety of substances that act in concert to promote vasodilation, antithrombosis, and anti-inflammation. ${ }^{4}$ Endothelial dysfunction, which causes cacophony in this finely tuned biological equilibrium, is a salient feature of atherosclerosis and occurs in the absence of angiographic evidence of coronary artery disease. On the flip side, one of the earliest indications of effective pharmacologic modulation of atherogenic risk is an improvement in endothelial function, resonating the significance of this endocrine organ in multiple cardiometabolic diseases. ${ }^{5}$

Endothelium-derived nitric oxide (NO) is constitutively generated from L-arginine by the enzymatic action of endothelial NO synthase (eNOS) and is a principal participant in the maintenance of normal endothelial function. Two other critical, albeit contradictory, vasoregulatory products of the endothelium are prostacyclin and endothelin-1. Disturbances in the integrity of the endothelial monolayer accordingly diminish NO and prostacyclin bioavailability and activity. Concurrently, endothelin-1-evoked effects are enhanced and escalated, thereby tipping the vascular homeostatic balance in favor of events encouraged by newly unveiled proatherogenic bioactive factors from the underlying smooth muscle layer. Any agent that further retards the events upstream and downstream of NO and prostacyclin and/or promotes those of endothelin-1 could therefore be detrimental in the diseased state.

CRP has been shown in in vitro models to inhibit endothelial cell eNOS transcription and translation, and limit eNOS activity and bioactivity, with ultimate reductions in basal and stimulated NO release. ${ }^{6,7}$ Prostacyclin secretion from endothelial cells was also appreciably reduced by CRP in vitro. ${ }^{8}$ In contrast, CRP substantially increased endothelin-1 and interleukin-6 release from human saphenous vein endothelial cells (HSVEC) in vitro. ${ }^{9}$ Additionally, CRP upregulated HSVEC protein and messenger RNA levels of the receptor for advanced glycation end products, which is postulated to participate in diabetes-linked endothelial dysfunction and atherosclerosis. ${ }^{10}$ Aberrations in the endothelium and its function can be provoked by oxidized LDL acting via the lectin-like oxidized LDL receptor-1 (LOX-1) protein. These abnormalities can be exacerbated by CRP, which has been found to elevate LOX-1 mRNA and protein levels. ${ }^{11}$ CRP has further been reported to facilitate endothelial cell apoptosis ${ }^{6}$ and attenuate key components involved in endothelial progenitor cell angiogenesis. ${ }^{12}$ Plasminogen activator inhibitor-1 and tissue plasminogen activator are fundamental to fibrinolysis and thrombosis. Whereas CRP increased mRNA, protein, and activity release of plasminogen activator inhibitor-1 from endothelial cells in vitro, the converse was true for tissue plasminogen activator. ${ }^{13,14} \mathrm{CRP}$ is thus prothrombotic and an antifibrinolytic. Taken together, the cumulative laboratory evidence suggests that human recombinant CRP, at concentrations known to predict vascular disease, triggers a rainbow of events in endothelial cells that bias the pro-inflammatory and pro-atherosclerotic phenotype.

In addition to modifying the endothelium, CRP has demonstrated well-documented influences on monocytes and smooth muscle cells. ${ }^{15}$ CRP induces the expression of macrophage chemoattractant protein-1 (MCP-1), intercellular adhesion molecule-1 (ICAM-1), and vascular cell adhesion molecule-1 (VCAM-1) in vitro. ${ }^{16,17}$ CRP deposition in the arterial wall appears to precede monocyte infiltration, and CRP is chemotactic for human monocytes. ${ }^{18}$ Although there is strong evidence suggesting that CRP exerts a proatherogenic influence via monocytes and macrophages, there also appears to be a more direct interaction of CRP with vascular tissues. Vascular smooth muscle cells are a target of proatherogenic modification by CRP, most notably via increased angiotensin type 1 receptor $\left(\mathrm{AT}_{1}-\mathrm{R}\right)$ protein, $\mathrm{AT}_{1}-\mathrm{R}$ mRNA, and $\mathrm{AT}_{1}-\mathrm{R}$ binding sites, while promoting smooth muscle cell migration and proliferation. ${ }^{19}$

Although there is some evidence that CRP is capable of directly and indirectly modulating endothelial function, the data have been somewhat confounding. Initial in vivo reports of a negative correlation between endothelial function and circulating levels of CRP in patients ${ }^{20,21}$ were brought into question by the demonstration that physiologically relevant concentrations of CRP directly caused vasodilation of isolated human internal thoracic arteries. ${ }^{22}$ More recently, Qamirani and colleagues ${ }^{18}$ demonstrated that 1-hour administration of exogenous CRP in perfused porcine coronary arterioles inhibited vasorelaxation elicited by 5-hydroxytryptamine in vitro. ${ }^{23}$ Aside from these reports, little is known about the manner in which long-term exposure to CRP may affect vasoreactivity and endothelial function. However, the latest preliminary studies from our group have suggested that endothelial function may be impaired in CRP overexpressing mice. The report by Momin and colleagues ${ }^{1}$ will belatedly spark interest and catalyze studies delving into this sorely neglected area of research.

The results presented in the study by Momin and associates $^{1}$ reinforce the concept that in patients slated for CABG procedures, statins are essential preoperative cardioprotective agents. Statins lower CRP levels profoundly, and 
this effect may be independently linked to their cardioprotectiveness. ${ }^{24,25}$ It is unknown what dosage of simvastatin these patients were prescribed. However, it does raise the consideration that in patients classified with high-risk CRP levels, more aggressive statin treatment (eg, $80 \mathrm{mg}$ atorvastatin or $20-40 \mathrm{mg}$ rosuvastatin), which would also suppress circulating CRP levels, may be necessary and should be initiated before CABG surgery. ${ }^{26}$ Side-effects (eg, rhabdomyolysis, hepatic dysfunction, myopathy) with such pharmacologic doses of statins are possible but minimal. The hunt to determine whether the eventual pharmacological panacea for SVG longevity lies with such intensive statin regimens or combinations of optimal LDLcontrolling statin dosages with anti-inflammatory agents is reliant on more large-scale longitudinal studies. The in vitro evidence demonstrating CRP as a vasorelaxant in thoracic arteries ${ }^{22}$ also prompts the need to perform parallel translational studies aimed at determining whether correlation observed between CRP and SVG endothelial function in the Momin and coworkers ${ }^{1}$ is mirrored in arterial grafts intended for CABGs. SVG patency is affected by multiple patient-specific and procedure-specific features, and elevated CRP levels is only one such factor.

\section{References}

1. Momin A, Melikian N, Wheatcroft SB, Grieve D, John LC, El Gamel A, et al. The association between saphenous vein endothelial function, systemic inflammation, and statin therapy in patients undergoing coronary artery bypass surgery. J Thorac Cardiovasc Surg. 2007;134: 335-41.

2. Poston RS, Gu J, Brown JM, Gammie JS, White C, Nie L, et al. Endothelial injury and acquired aspirin resistance as promoters of regional thrombin formation and early vein graft failure after coronary artery bypass grafting. J Thorac Cardiovasc Surg. 2006;131:122-30.

3. Ridker PM, Rifai N, Rose L, Buring JE, Cook NR. Comparison of C-reactive protein and low-density lipoprotein cholesterol levels in the prediction of first cardiovascular events. N Engl J Med. 2002; 347:1557-65.

4. Quyyumi AA. Endothelial function in health and disease: new insights into the genesis of cardiovascular disease. Am J Med. 1998;105:32S-9S.

5. Wolfrum S, Jensen KS, Liao JK. Endothelium-dependent effects of statins. Arterioscler Thromb Vasc Biol. 2003;23:729-36.

6. Verma S, Wang CH, Li SH, Dumont AS, Fedak PW, Badiwala MV, et al. A self-fulfilling prophecy: C-reactive protein attenuates nitric oxide production and inhibits angiogenesis. Circulation. 2002;106: 913-9.

7. Mineo C, Gormley AK, Yuhanna IS, Osborne-Lawrence S, Gibson LL, Hahner L, et al. FegammaRIIB mediates C-reactive protein inhibition of endothelial NO synthase. Circ Res. 2005;97:1124-31.

8. Venugopal SK, Devaraj S, Jialal I. C-reactive protein decreases prostacyclin release from human aortic endothelial cells. Circulation. 2003;108:1676-8.

9. Verma S, Li SH, Badiwala MV, Weisel RD, Fedak PW, Li RK, et al. Endothelin antagonism and interleukin-6 inhibition attenuate the proatherogenic effects of C-reactive protein. Circulation. 2002;105: $1890-6$.

10. Zhong Y, Li SH, Liu SM, Szmitko PE, He XQ, Fedak PW, et al. $\mathrm{C}$-reactive protein upregulates receptor for advanced glycation end products expression in human endothelial cells. Hypertension. 2006; 48:504-11.

11. Li L, Roumeliotis N, Sawamura T, Renier G. C-reactive protein enhances LOX-1 expression in human aortic endothelial cells: relevance of LOX-1 to C-reactive protein-induced endothelial dysfunction. Circ Res. 2004;95:877-83.

12. Verma S, Kuliszewski MA, Li SH, Szmitko PE, Zucco L, Wang CH, et al. C-reactive protein attenuates endothelial progenitor cell survival, differentiation, and function: further evidence of a mechanistic link between C-reactive protein and cardiovascular disease. Circulation. 2004;109:2058-67.

13. Devaraj S, Xu DY, Jialal I. C-reactive protein increases plasminogen activator inhibitor-1 expression and activity in human aortic endothelial cells: implications for the metabolic syndrome and atherothrombosis. Circulation. 2003;107:398-404.

14. Singh U, Devaraj S, Jialal I. C-reactive protein decreases tissue plasminogen activator activity in human aortic endothelial cells: evidence that C-reactive protein is a procoagulant. Arterioscler Thromb Vasc Biol. 2005;25:2216-21.

15. Verma S, Devaraj S, Jialal I. Is C-reactive protein an innocent bystander or proatherogenic culprit? C-reactive protein promotes atherothrombosis. Circulation. 2006;113:2135-50.

16. Pasceri V, Willerson JT, Yeh ET. Direct proinflammatory effect of C-reactive protein on human endothelial cells. Circulation. 2000;102: 2165-8.

17. Pasceri V, Cheng JS, Willerson JT, Yeh ET. Modulation of C-reactive protein-mediated monocyte chemoattractant protein-1 induction in human endothelial cells by anti-atherosclerosis drugs. Circulation. 2001; 103:2531-4.

18. Torzewski M, Rist C, Mortensen RF, Zwaka TP, Bienek M, Waltenberger J, et al. C-reactive protein in the arterial intima: role of C-reactive protein receptor-dependent monocyte recruitment in atherogenesis. Arterioscler Thromb Vasc Biol. 2000;20:2094-9.

19. Wang CH, Li SH, Weisel RD, Fedak PW, Dumont AS, Szmitko P, et al. C-reactive protein upregulates angiotensin type 1 receptors in atherogenesis. Circulation. 2003;107:1783-90.

20. Cleland SJ, Sattar N, Petrie JR, Forouhi NG, Elliott HL, Connell JM. Endothelial dysfunction as a possible link between C-reactive protein levels and cardiovascular disease. Clin Sci (Lond). 2000;98:531-5.

21. Fichtlscherer S, Rosenberger G, Walter DH, Breuer S, Dimmeler S, Zeiher AM. Elevated C-reactive protein levels and impaired endothelial vasoreactivity in patients with coronary artery disease. Circulation. 2000;102:1000-6.

22. Sternik L, Samee S, Schaff HV, Zehr KJ, Lerman LO, Holmes DR, Herrmann J, Lerman A. C-reactive protein relaxes human vessels in vitro. Arterioscler Thromb Vasc Biol. 2002;22:1865-8.

23. Qamirani E, Ren Y, Kuo L, Hein TW. C-reactive protein inhibits endothelium-dependent NO-mediated dilation in coronary arterioles by activating $\mathrm{p} 38$ kinase and NAD(P)H oxidase. Arterioscler Thromb Vasc Biol. 2005;25:995-1001.

24. Ray KK, Cannon CP, Cairns R, Morrow DA, Rifai N, Kirtane AJ, et al. Relationship between uncontrolled risk factors and C-reactive protein levels in patients receiving standard or intensive statin therapy for acute coronary syndromes in the PROVE IT-TIMI 22 trial. $J$ Am Coll Cardiol. 2005;46:1417-24.

25. Albert MA, Danielson E, Rifai N, Ridker PM. Effect of statin therapy on C-reactive protein levels: the pravastatin inflammation/CRP evaluation (PRINCE): a randomized trial and cohort study. JAMA. 2001; 286:64-70.

26. Schwartz GG, Olsson AG. The case for intensive statin therapy after acute coronary syndromes. Am J Cardiol. 2005;96:45F-53F. 